\title{
LVRT Research of PMSG Wind Turbine Using Feedback Linearization
}

\author{
Jie Wei ${ }^{1}$, Zhenyu Lin ${ }^{2}$, Nian Liu ${ }^{1}$ \\ ${ }^{1}$ Smart Grid Key Laboratory of Sichuan Province, School of Electrical Engineering and Information, \\ Sichuan University, Chengdu, China \\ ${ }^{2}$ College of Electrical and Electronic Engineering, Huazhong University of Science and Technology, Wuhan, China \\ Email: vajay4920@sina.com
}

Received February, 2013

\begin{abstract}
Analyzing the wind turbine with a direct-driven PMSG, this paper proposes a low voltage ride through scheme of PMSG wind power systems based on feedback linearization. The DC-Link voltage is controlled by the generator-side converter rather than the grid-side converter. Considering the nonlinear relationship between the DC-Link voltage and the generator rotor speed, the controller of DC-Link voltage uses a feedback linearization technology. The grid-side converter which controls the grid active power according to the maximum power point tracking adds a judgment link for the generator speed reference. The model of 2 MW PMSG wind power system was simulated by using PSCAD. The simulation result has verified the validity of the proposed control scheme.
\end{abstract}

Keywords: PMSG; DC-Link Voltage; Converter; PSCAD

\section{Introduction}

Among various renewable energy sources, the application of wind power generation in the world has been rapidly growing. Unlike the DFIG (double fed induction generator) wind power system, direct-drive PMSG (permanent magnet synchronous) wind power system have some advantages such as simple structure, high power generation efficiency, high precision and high operating reliability[1].

Because of the growing proportion of the wind field, the grid-connected conditions of wind power generator are more and more important. In recent years, many countries in the world have promulgated special interconnection rules and processes for large-scale wind power units through a grid code [2,3].

Scholars at home and abroad have proposed a large number of schemes for the LVRT (low voltage ride through) capability of the DFIG wind turbines [4-7],but researches on direct-drive PMSG is very limited. Reference [8] increased the speed of the generator and reduced the converter input power in order to realize the LVRT, but the improving level is very limited and the DC-Link voltage may exceed the limit. In [9] and [10], Crowbar circuit absorbed the unbalanced power in the power grid fault, however, in this way, the unbalanced power would be completely waste, which needing the support of load

*The project sponsored by Science and Technology Department of Sichuan Province(2011GZ0036). and heat dissipation. The STATCOM can be used to supply the reactive power compensation for wind power turbines in the power grid fault [11], however, when the fault occurs and ends, the cut-in and cut-out of the STATCOM make the control more complex, and investment cost is also great.

For PMSG wind power system with back-to-back PWM converters, in the conventional control method [12], the generator rotor speed is controlled by the generator- side converter, and the grid-side converter control the DC-Link voltage. Considering the nonlinear relationship between the DC-Link voltage and the generator rotor speed, this paper proposes an improved control method of the power conversion. The DC-Link voltage is maintained within regular range by the generator-side converter which introduces feedback linearization control technology. The generator speed reference $\omega^{*}$ is output by the grid-side converter for the maximum power point tracking, and the ultimate value $\omega_{w}{ }^{*}$ is got after comparative judgment with $\omega^{*}$.

\section{Mathematical Model of PMSG Wind Power Sysrem}

According to the aerodynamics, the simplified mathematical model of wind turbine is formulated as[13]:

$$
\left\{\begin{array}{l}
P_{w}=\frac{1}{2} \rho \pi R^{2} v^{3} C_{p}(\theta, \lambda) \\
\lambda=\omega_{w} R / v
\end{array}\right.
$$


where $P_{w}$ is the extracted wind power, $\rho$ the air density, $v$ the wind speed, $R$ the rotor radius, $\omega_{w}$ the wind turbine speed, $C_{p}$ the efficiency coefficient.

In the synchronous d-q coordinates, the mathematical model of PMSG are[14]:

$$
\left\{\begin{array}{l}
u_{s d}=R_{s} i_{s d}+L_{d} \frac{d i_{s d}}{d t}-L_{q} \omega i_{s q} \\
u_{s q}=R_{s} i_{s q}+L_{q} \frac{d i_{s q}}{d t}+L_{d} \omega i_{s d}+\omega \psi
\end{array}\right.
$$

where $u_{s d}$ and $u_{s q}$ are the d-q stator voltage, $i_{s q}$ and $i_{s q}$ the d-q stator currents, $R_{s}$ and $L_{s}$ are stator resistance and inductance, $\omega$ the generator speed, $\psi$ magnet flux.

Using the control strategy of $i_{d}=0$, the generator electromagnetic torque is:

$$
T_{e}=\frac{3}{2} p_{n} \psi i_{s q}
$$

where $p_{n}$ is the number of pole pairs.

Neglecting the loss of converter and generator, the generator power and the DC-Link capacitor $C$ are:

$$
\begin{gathered}
P_{g}=P_{w}-J \omega_{w} \frac{d \omega_{w}}{d t} \\
P_{c}=u_{d c} C \frac{d u_{d c}}{d t}=P_{g}-P_{g r i d}
\end{gathered}
$$

where $P_{g}$ is the generator power, $u_{d c}$ the DC-Link voltage, $P_{\text {grid }}$ the gird power.

Combining Equations (4) and (5), a dynamic equation can be introduced:

$$
u_{d c} C \frac{d u_{d c}}{d t}=\frac{1}{2} \rho \pi R^{5} C_{p} \frac{1}{\lambda^{3}} \omega_{w}^{3}-J \omega_{w} \frac{d \omega_{w}}{d t}-P_{g r i d}
$$

In the above Equation (6), the nonlinear relationship between $u_{d c}$ and $\omega_{w}$ can be shown.

\section{Control Strategy}

\subsection{Control Scheme of the Grid-side PWM Converter}

When the wind turbine power $P$ is less than the rated power, the rotor speed reference $\omega_{w}{ }^{*}$ can be expressed as follows by $P[15]$ :

$$
\omega_{w}^{*}=-0.67 P^{2}+1.42 P+0.51
$$

According to Equation (7) for the MPPT, the rotor speed reference $\omega_{w}{ }^{*}$ can be got.

As shown in Figure 1, when the rotor speed is greater than 1 p.u, $\omega_{w}^{*}$ is set to 1 in order to make the generation system can according to the active power demand of the gird-side ensure that the generator rotor work in the best reference.

The control block diagram of the grid-side PWM converter is shown in Figure 2.

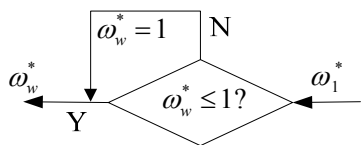

Figure 1.Control block diagram of the grid-side PWM converter.

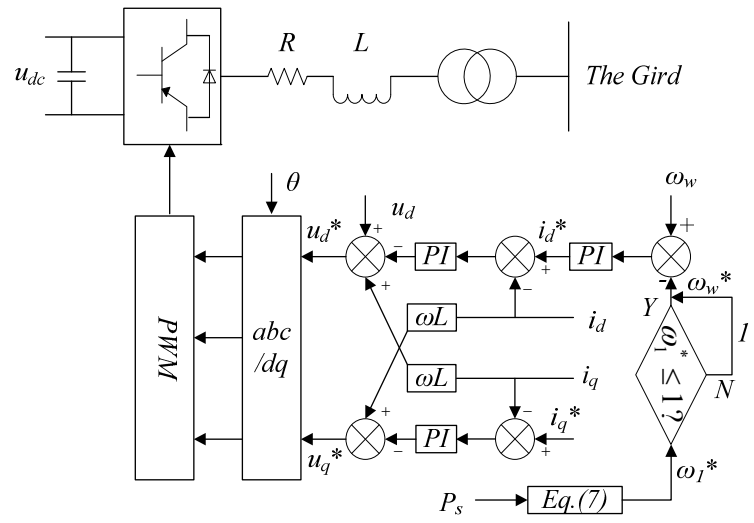

Figure 2.Control block diagram of the grid-side PWM converter.

\subsection{Control Scheme of the Generator-side PWM Converter}

The state equations of a single input and single output system can be represented as follows:

$$
\left\{\begin{array}{l}
\dot{x}=f(x)+g(x) u \\
y=h(x)
\end{array}\right.
$$

Where $x$ is the state vector, $u$ the control input, $y$ the output, $h$ the smooth scalar function, $f$ and $g$ are the $n$ dimensional smooth vector field.

The nonlinear Equations (4) (5) can be written in the state equations as follows:

$$
\left[\begin{array}{c}
\dot{u_{d c}} \\
\dot{\omega}_{w}
\end{array}\right]=\left[\begin{array}{c}
-\frac{1}{u_{d c} C} P_{\text {grid }} \\
\frac{1}{J \omega_{w}} P_{w}
\end{array}\right]+\left[\begin{array}{c}
\frac{1}{u_{d c} C} \\
-\frac{1}{J \omega_{w}}
\end{array}\right] P_{g}
$$

For the system design methodology, the DC-Link voltage is used as the control input. In order to realize the linear process, the output $y$ is for the difference.

$$
\dot{y}=\Delta h(f+g \cdot u)=L_{f} h(x)+L_{g} h(x) \cdot u
$$

where $L_{f} h(x)$ is the first order Lie derivatives of $h(x)$ along $f, L_{g} h(x)$ along $g$. Here, the first order Lie derivatives is defined as follows:

$$
\begin{aligned}
& L_{f} h=\Delta h f=\frac{\partial h}{\partial x} \cdot f \\
& L_{g} h=\Delta h g=\frac{\partial g}{\partial x} \cdot f
\end{aligned}
$$


Without loss of generality, Equation (12) is given as:

$$
\left\{\begin{array}{l}
L_{g} h(x)=A(x) \\
L_{f} h(x)=B(x)
\end{array}\right.
$$

Hence, Equation (13) can be derived from Equations (10) and (12).

$$
\dot{y}=B(x)+A(x) \cdot u
$$

Combining Equations (9) and (13), Equation (14) is represented as follows:

$$
\left\{\begin{array}{l}
A(x)=-\frac{1}{u_{d c} C} P_{g r i d} \\
B(x)=\frac{1}{u_{d c} C}
\end{array}\right.
$$

Feedback law can generally be written as:

$$
u=\frac{1}{A(x)}[-B(x)+v]
$$

where $v$ is the equivalent input.

In order to eliminate and reduce the steady-state error of the system, Equation (16) can be deduced from the PI control.

$$
v=\dot{y}_{r e f}-k_{1}\left(y-y_{r e f}\right)-k_{2} \int\left(y-y_{r e f}\right) d t
$$

where $y_{r e f}$ is the reference value, $k_{1}$ and $k_{2}$ are the adjustable gains.

The control block diagram of the nonlinear DC-Link voltage and the generator-side PWM converter is shown in Figure 3.

\section{Simulation and Analysis}

To verify the validity of the proposed algorithm, this paper simulates 2 MW PMSG wind power system based on PSCAD. Imitating the grid connection point voltage drops to $50 \%$ in $1 \mathrm{~s}-1.5 \mathrm{~s}$, the proposed new method is compared with the conventional method in this paper. The system parameters are as follow.

- PMSG: Stator rated voltage $690 \mathrm{~V}$, Magnetic induction $1 p . u$, Stator phase resistance $0.008 p . u$, Directaxis inductance $X_{\mathrm{d}} 0.062$ p.u, Quadrature axis inductance $X_{\mathrm{q}} 1.1477$ p.u.

- Wind Turbine: Air density $1.225 \mathrm{~kg} / \mathrm{m}^{3}$, Rated wind speed $10 \mathrm{~m} / \mathrm{s}$.

- Converter: DC-Link voltage $1100 \mathrm{~V}$, Rated output voltage $690 \mathrm{~V}$, Reactive power setting value $0 \mathrm{Mvar}$, Grid frequency $50 \mathrm{~Hz}$.

The grid output power is minished along with the grid connection point voltage drops to $50 \%$, which, at the same time, causing the generator output power reduction. The unbalanced power between the grid-side and the generator-side will cause DC-Link voltage rise to 1.3 p.u. The performance of DC-Link voltage $u_{\mathrm{dc}}$ for the conventional method is as shown in Figure 4(b). However, in the new method, $u_{\mathrm{dc}}$ is almost constant, as shown in Figure 5(b). Because of the unbalanced power, a portion of energy has stored in the wind turbine, thus, the rotor speed $\omega_{\mathrm{w}}$ would enhance. But the rising is less than 0.08 p. $u$ which is within the safe range, as shown in Figure 4(c) and Figure 5(c). With the failure to eliminate, it turns back to the normal value.

\section{Conclusions}

This paper proposes a low voltage ride through scheme of PMSG wind power systems based on feedback linearization. The DC-Link voltage is maintained and regulated by generator-side converter. The control scheme of the generator-side converter has been designed using

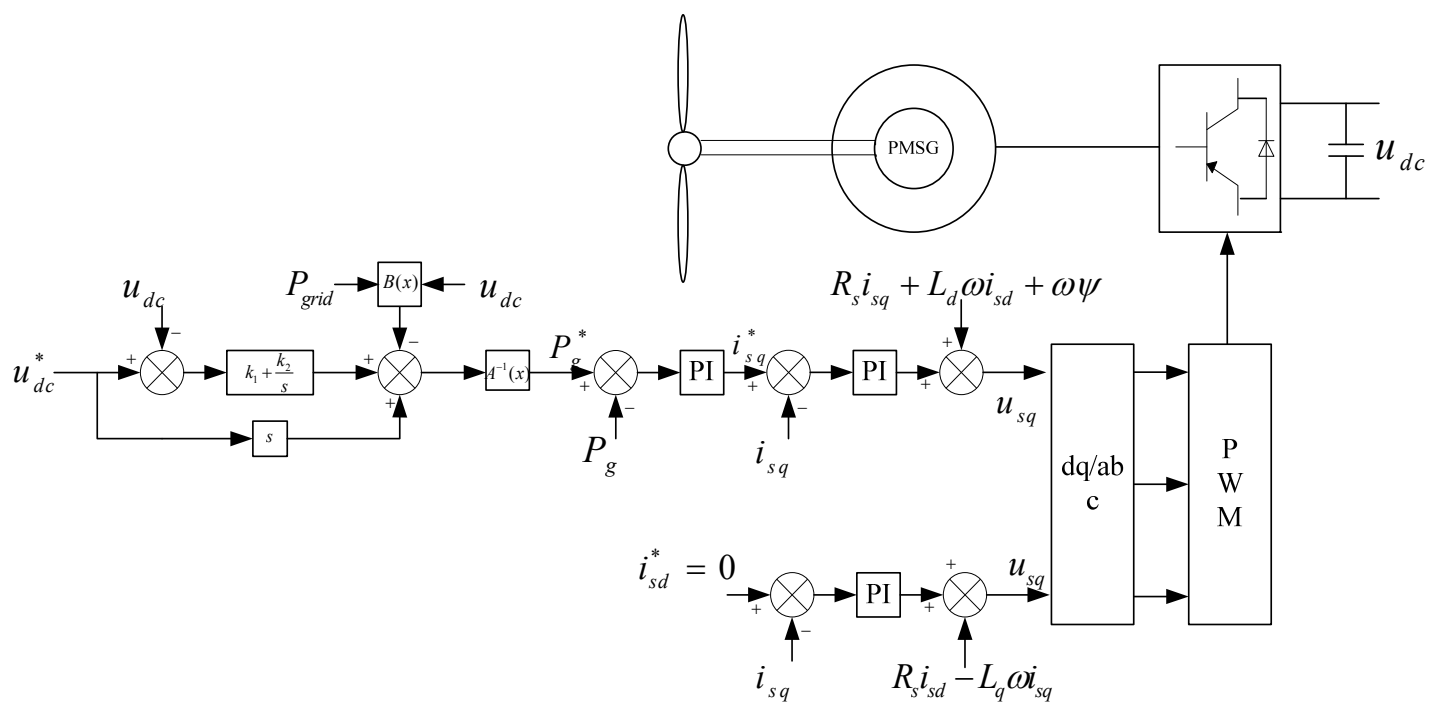

Figure 3.Control block diagram of the grid-side PWM converter. 


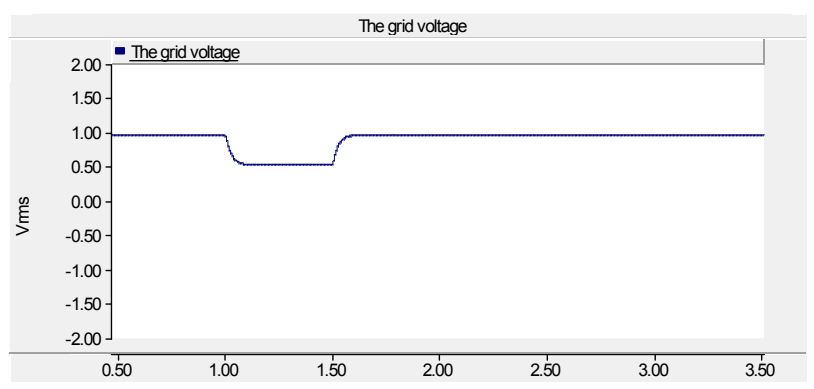

(a) the RMS values of the gird voltage

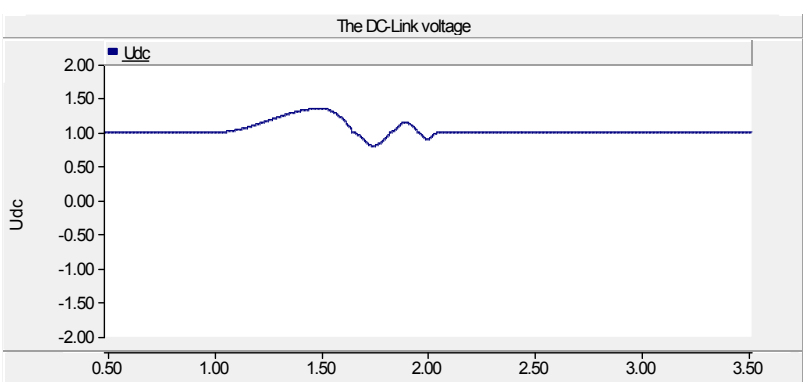

(b) the RMS values of the gird voltage

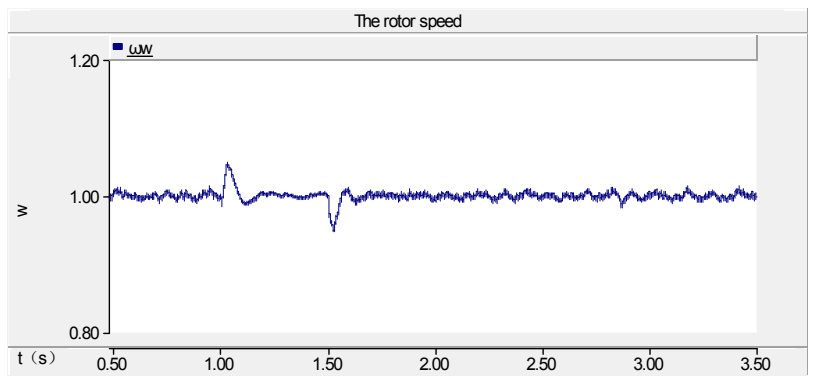

(c) the rotor speed $\omega_{w}$

Figure 4. Simulation of the conventional method for power system fault.

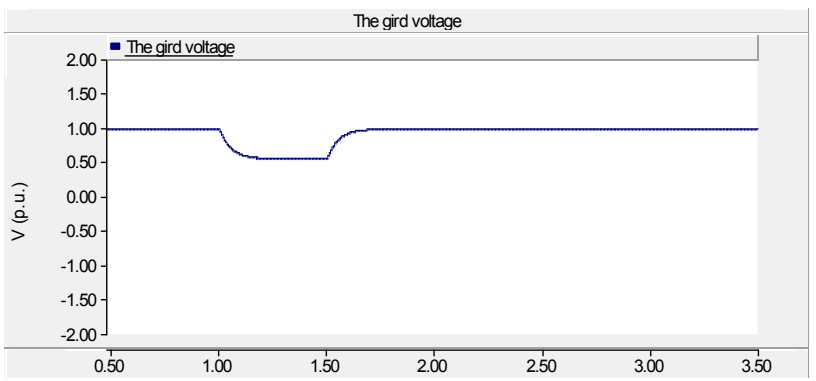

(a) the RMS values of the gird voltage

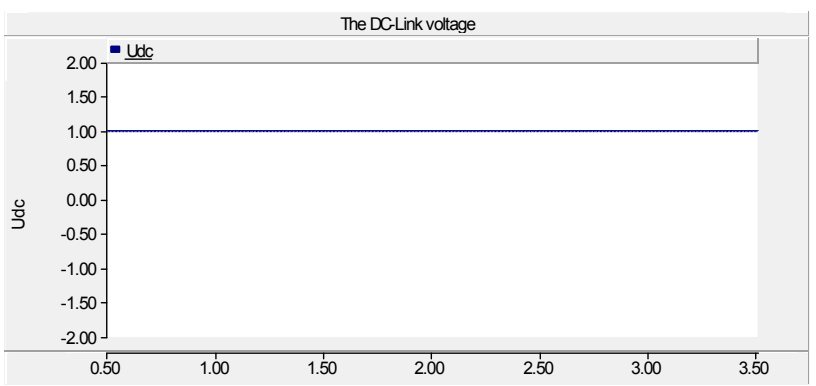

(b) the RMS values of the gird voltage

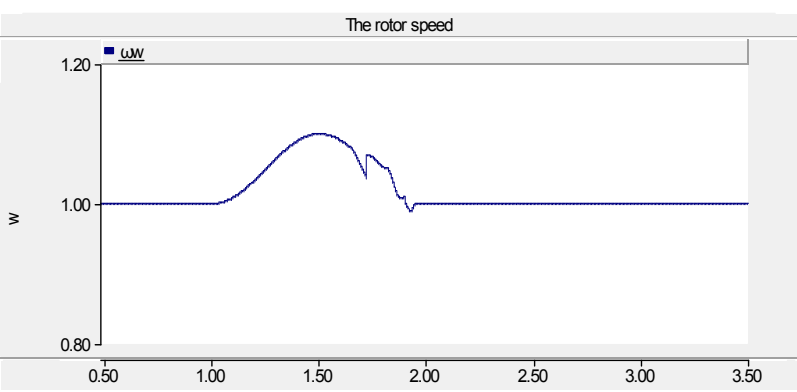

(c) The rotor speed $\omega_{w}$

Figure 5. Simulation of the new method for power system fault.

feedback linearization, and the grid-side converter regulates the power for MPPT. The simulation result demonstrates the validity of the method. When the grid voltage sags to $50 \%$, the proposed algorithm can effectively decrease the rising of DC-Link voltage, and keep it almost invariable so that the LVRT capability of PMSG wind power systems is improved. Wind turbines can still run in parallel operation until return to normal operating condition during power system fault.

\section{REFERENCES}

[1] H. Polinder, F. F. A van der Pijl and P. Tavner, "Comparison of Direct-drive and Geared Generator Concepts for Wind Turbines," IEEE Transactions on Energy Conversion, Vol. 21, No. 2, 2006, pp. 725-733.

doi:10.1109/TEC.2006.875476

[2] C. Saniter and J. Janning, "Test Bench for Grid Code Simulations for Multi-MW Wind Turbines, Design and Control," IEEE Transactions on Power Electronics, Vol. 23, No. 4, 2008, pp. 1707-1715. doi:10.1109/TPEL.2008.925425

[3] GB/T2008-327 "State Power Grid Corporation of Technical Requirements for Wind Farms".

[4] H. M. Li, X. Y. Zhang, Y. Wang and X. R. Zhu, "Virtual Inertia Control of DFIG-based Wind Turbines Based on the Optimal Power Tracking," Proceedings of the CSEE, Vol. 32, No. 7, 2012, pp. 32-39.

[5] L. Liang, J. L. Li and H. H. Xu, " Reactive Power Control Strategy for Doubly-Fed Induction Wind Power Generation System Under Fault in Power Network," Power System Technology, Vol. 32,No. 11, 2008, pp. 70-73,

[6] J. H. Zhang, J. Wang and X. Y. Chen, "Analysis of DFIG-based Wind Generation LVRT Control Strategy," Power System Protection and Control, Vol. 39, No. 21, 2011, pp. 28-33.

[7] G. Q. Li, Y. N. Qian and M. X. Liu, "Research on Low Voltage Ride through Control Strategies for Doubly Fed Induction Generator Based on Sliding Mode Control," Power System Protection and Control, Vol. 40, No. 1,2012, pp. 5-11.

[8] J. Morren, J. T. G. Pierik and S. W. H. De Haan, "Voltage 
Dip ride-through Control of Direct-drive Wind Turbines," Proceedings of the 39th International Universities Power Engineering Conference, Bristol, UK, 6-8 September, 2004, pp. 934-938.

[9] C. Abbey and G. Joos, "Effect of Low Voltage Ride through (LVRT) Characteristic on Voltage Stability," Proceedings of IEEE Power Engineering Society General Meeting, San Francisco, CA, USA, Vol. 2, 2005, pp. 1901-1907.

[10] W. Li, C. Abbey and G. Joos, "Control and Performance of Wind Turbine Generators Based on Permanent Magnet Synchronous Machines Feeding a Diode Rectifier," Proceedings of the 37th IEEE Power Electronics Specialists Conference, Jeju, Korea, 2006, pp.1-6.

[11] B. Singh, R.. Saha, A. Chandra and K. Al-Haddad, "Static Synchronous Compensators (STATCOM): A Review," IET Power Electronics, Vol. 2, No. 4, 2009, pp. 297-324. doi:10.1049/iet-pel.2008.0034

[12] N. W. Miller, J. J. Sanchez-Gasca and W. W. Price, "Dynamic Modeling of GE 1.5 and 3.6 MW Wind Turbine
Generators for Stability Simulations," IEEE Power Engineering Society General Meeting, Vol. 3, 2003, pp.19771983.

[13] J. Yao, Y. Liao and K. Zhuang, "Coordinated Control Strategy of Back-to-back PWM Converter for Permanent Magnet Direct-driven Wind Turbine," Automation of Electric Power Systems, Vol. 32, No. 20, 2008, pp.88-107.

[14] M. Yin, G. Y. Li, J. C. Zhang, et al., "Modeling and Control Strategies of Directly Driven Wind Turbine with Permanent Magnet Synchronous Generator," Power System Technology, Vol. 31, No. 15, 2007, pp. 61-65.

[15] J. G. Slootweg, S. W. H. de Haan and H. Polinder, "General Model for Representing Variable Speed Wind turbines in Power System Dynamics Simulations," IEEE Transactions on Power System, Vol. 18, No. 1, 2003, pp. 144-151. doi.:10.1109/TPWRS.2002.807113 